\title{
ТЕКТОНИЧЕСКИЕ НАРУШЕНИЯ В ТООМПЕА (ВЫШГОРОД ТАЛЛИНА)
}

D. HEINSALU. TEKTOONILISED RIKKED TOOMPEAL (TALLINN)

D. HEINSALU. DISLOCATIONS IN THE OUTLIER TOOMPEA (TALLINN)

Доплейстоценовый денудационный останег Тоомпеа имеет длину около 500 м, ширину $250 \mu$ и высоту до $48 \mu$. В верхней части он сложен известняками, местами обнажающимися на отвесных уступах, а в нижней - аргиллитами и песчаниками ордовика. Слои этих пород залегают моноклинально, падая в южном направлении под углом в среднем $0^{\circ} 15^{\prime}$.

В обнажении уступа (рис. 1, обн. 1), который находится в 2050 м севернее башни «Длинный Герман», наблюдается повышенный угол наклона известняков $\left(5-10^{\circ}\right.$ на юг) и прослеживается семь мелких сбросов, развитых по крутопадающим трещинам. Последние расположены на расстоянии $1-8$ м друг от друга и имеют северозападное или субши-

Рис. 1. Тектонические нарушения; роза-диаграммы и геологический разрез останца Tоомпеа: 1 - крутой склон или уступ, 2 - зоны нарушений, 3 - известняк, 4 оолитовый известняк.

Горизонты: $\mathrm{O}_{1} \mathrm{vl}$ - волховский, $\mathrm{O}_{2}$ as - азериский, $\mathrm{O}_{2} \mathrm{Is}$ - ласнамягиский,

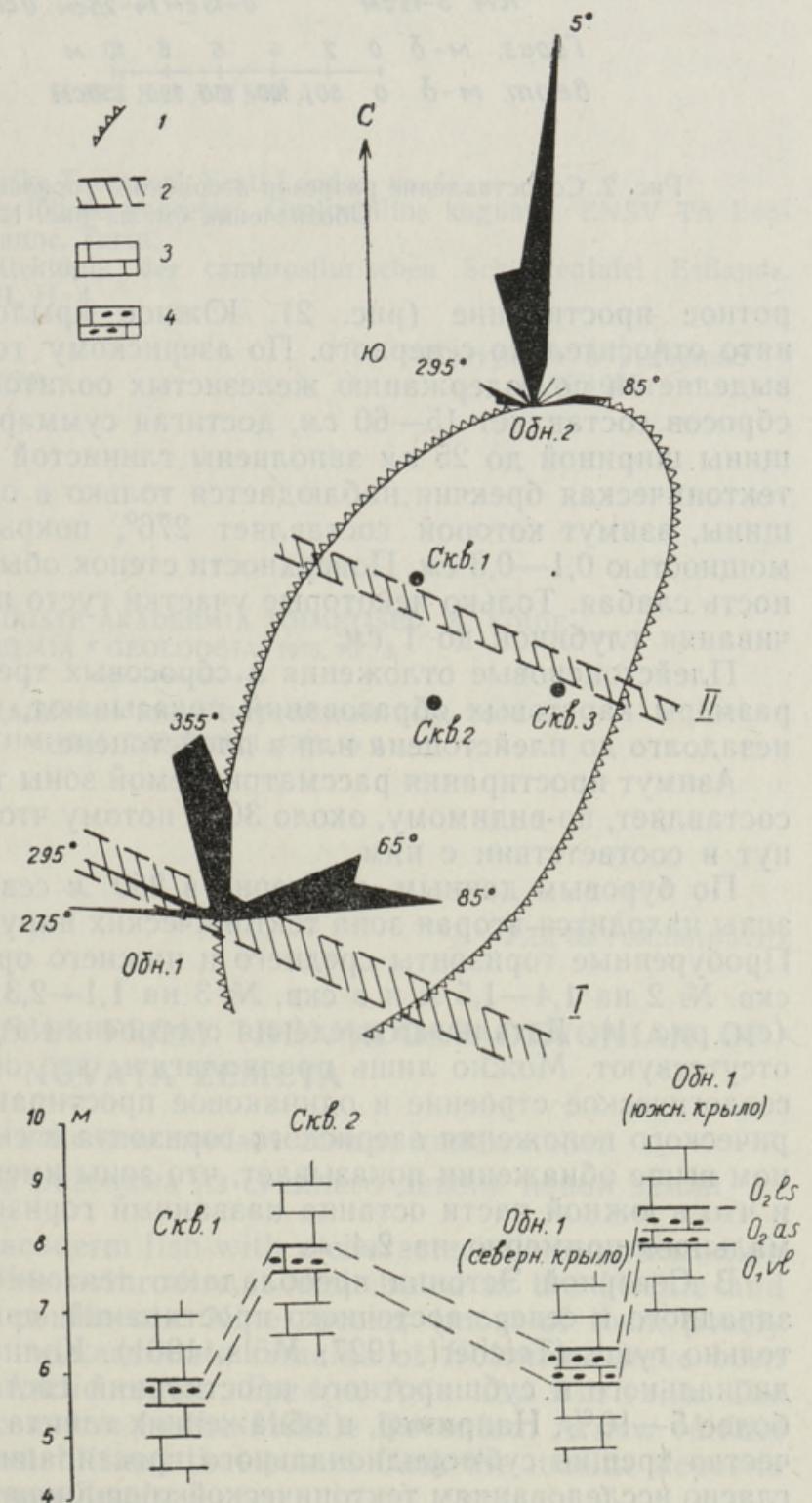




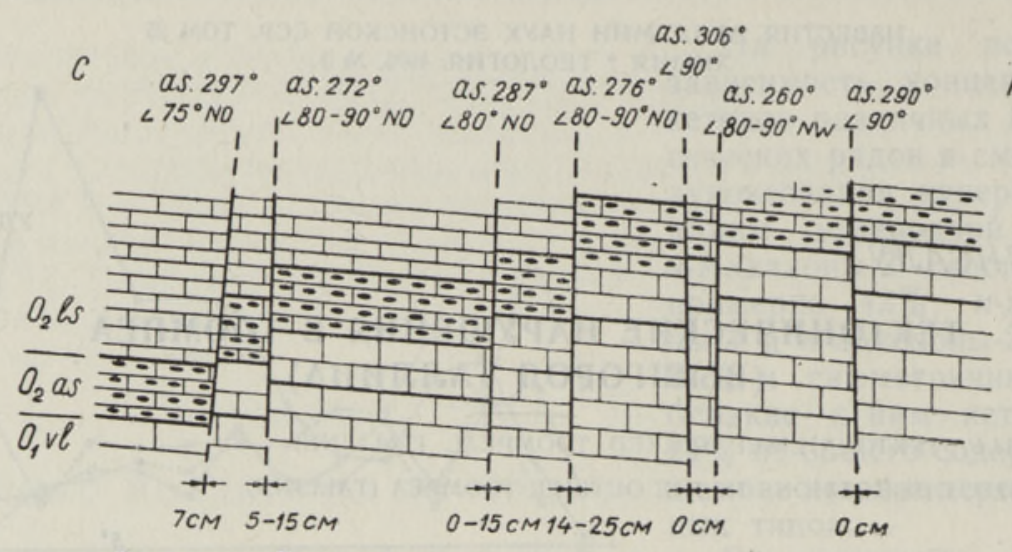

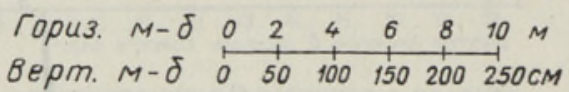

Рис. 2. Сопоставление разрезов азериского горизонта в останце Тоомпеа. Обозначения см. на рнс. 1.

ротное простирание (рис. 2). Южное крыло всех сбросов приподнято относительно северного. По азерискому горизонту, который четко выделяется по содержанию железистых оолитов, амплитуда отдельных сбросов составляет 15-60 cм, достигая суммарно 2,2 щины шириной до 25 см заполнены глинистой буровато-серой мореной; тектоническая брекчия наблюдается только в одной из них. Стенки трещины, азимут которой составляет $276^{\circ}$, покрыты кальцитовой коркой мощностью $0,1-0,3$ см. Поверхности стенок обычно ровные, закарстованность слабая. Только некоторые участки густо покрыты ямками выщелачивания глубиной до 1 см.

Плейстоценовые отложения в сбросовых трещинах и незначительные размеры карстовых образований показывают, что сбросы образовались незадолго до плейстоцена или в плейстоцене.

Азимут простирания рассматриваемой зоны тектонических нарушений составляет, по-видимому, около $300^{\circ}$, потому что наибольший сброс вытянут в соответствии с ним.

По буровым данным, прймерно в 250 м северо-восточнее описанной зоны находится вторая зона тектонических нарушений (Künnapuu, 1970). Пробуренные горизонты среднего и нижнего ордовика залегают здесь в скв. № 2 на 1,4-1,5 $м$ и в скв. № 3 на 1,1-2,3 $м$ выше, чем в скв. № 1 (см. рис. 1). Детальные сведения о строении этой зоны нарушений пока отсутствуют. Можно лишь предполагать, что обе зоны имеют сходное геологическое строение и одинаковое простирание. Сравнение гипсометрического положения азериского горизонта в скв. №№ 1 и 2 и в описанном выше обнажении показывает, что зоны имеют ступенчатый характер и что в южной части останца названный горизонт находится выше нормального примерно на 2,4 $м$.

В Северной Эстонии преобладают тектонические трещины северозападного и северо-восточного простираний, причем сеть первых значительно гуще (Teichert, 1927; Möls, 1961). Количество трещин субмеридионального и субширотного простираний составляет, как правило, не более 5-10\%. Например, в обнажениях глинта восточнее Таллина количество трещин субмеридионального простирания не превышает $4 \%$. Согласно исследованиям тектонической трещиноватости, в обнажении Выш- 
города вблизи башни «Длинный Герман» количество трещин субмеридионального простирания составляет около $20 \%$, субширотного - около $19 \%$ и северо-восточного - около $18 \%$. (Относительное количество трещин северо-западного простирания не устанавливалось, поскольку обнажение имеет то же направление.)

В обнажениях северного склона Вышгорода количество субмеридиональных трещин достигает почти $49 \%$ (см. рис. 1, обн. 2). Следовательно, для исследованных участков Вышгорода характерна относительно густая сеть трещин субмеридионального и субширотного простираний. Это обусловлено, очевидно, наличием зон тектонических нарушений. Такой вывод совпадает с литературными данными, согласно которым повышенное количество трещин отмеченных простираний наблюдается на тех территориях, где моноклинальное залегание слоев нарушено (Геология СССР, т. 1,1971$)$.

\title{
Л И Т Е Р А У Р А
}

Геология СССР, т. 1. 1971.

$\mathrm{K}$ ü n n a p u u S. 1970. Lasuvusrike Toompeal. Eesti Loodus, nr. 4.

Möls E. 1961. Eesti aluspõhja lōhede geneesist. Geoloogiline kogumik. ENSV TA Loodusuurijate seltsi väljaanne. Tartu.

Teichert C. 1927. Die Klufttektonik der cambrosilurischen Schichtentafel Estlands. Geol. Rundschau, XVIII, H. 4.
Ннститут геологии
Академии наук Эстонской ССР
Поступила в редакцию
$16 / \mathrm{X} 1975$

\author{
EESTI NSV TEADUSTE AKADEEMIA TOIMETISED, 25, KOIDE \\ KEEMIA * GEOLOOGIA. 1976, Nr. 3 \\ ИЗВЕСТИЯ АКАДЕМИИ НАУК ЭСТОНСКОИ ССР. ТОМ 25 \\ ХИМИЯ * ГЕОЛОГИЯ. 1976, № 3
}

Elga MARK-KURIK

удК $567: 551.734(470.117)$

\section{ARTHRODIRE HOLONEMA FROM THE MIDDLE DEVONIAN OF NOVAYA ZEMLYA}

ELGA MARK-KURIK. ARTRODIIR HOLONEMA NOVAJA ZEMLJA KESKDEVONIST

ЭЛЬа М МАК-КУРИК. АРТРОДИРА НОLONЕМА ИЗ СРЕДНЕГО ДЕВОНА НОВОИ ЗЕМЛИ

Holonema is a large placoderm fish with a characteristic ornamentation of ridges and tubercles. This arthrodire is distributed in the Middle and Late Devonian of several continents. Nine species (most of them poorly known) and a number of indeterminate remains of Holonema have been found in North America, Arctic region, Europe, Asia and Australia. The genus seems to be more common in the Middle Devonian. A new Middle Devonian species can be established that comes from the marine deposits of the southern part of Novaya Zemlya. 